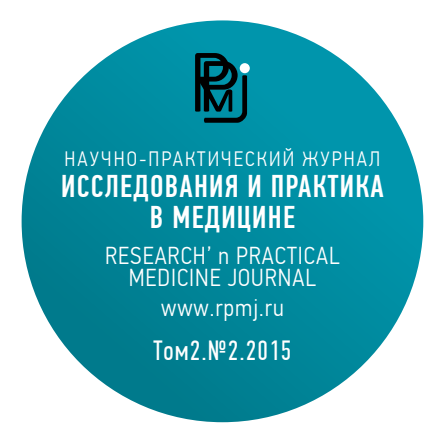

Ключевые слова:

научное исследование,

инновационная деятельность, интеллектуальная собственность, патент, изобретение,

полезная модель,

клиническая онкология

Keywords:

research, innovation, intellectual property, patent, invention, utility model, clinical oncology

DOI: 10.17709/2409-2231-2015-2-2-53-62

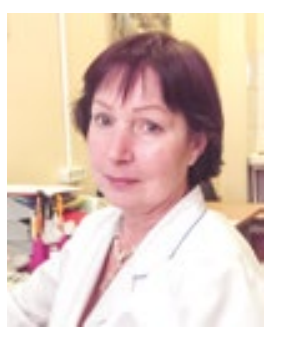

Для корреспонденции:

Александрова Лариса Митрофановна -

к.б.н., заведующая отделением координации и внедрения научных исследований МНИОИ им. П.А. Герцена - филиала ФГБУ «НМИРЦ» Минздрава России

Адрес: 125284, Российская Федерация,

Москва, 2-ой Боткинский проезд, дом 3.

Телефон: +7(495)945-14-92

E-mail: mnioi.alex@mail.ru

Статья поступила 18.05.2015,

принята к печати 11.06.2015

For correspondence:

Alexandrova Larisa Mitrofanovna -

PhD., head of department of coordination and implementation of research, P. A.

Hertsen Moscow Oncology Research Institute

branch of the National Medical Research

Radiological Centre of the Ministry of Health

of the Russian Federation

Address: 3, 2 Botkinskiy proezd, Moscow,

Russian Federation, 125284

Tel: +7(495)945-14-92

E-mail:mnioi.alex@mail.ru

The article was received 18.05.2015

accepted for publication 11.06.2015

\section{РЕАЛИЗАЦИЯ В КЛИНИЧЕСКОЙ ОНКОЛОГИЧЕСКОЙ ПРАКТИКЕ РЕЗУЛЬТАТОВ ИННОВАЦИОННЫХ НАУЧНЫХ ИССЛЕДОВАНИЙ}

\author{
Каприн А.Д. ${ }^{1}$, Александрова Л.М. ${ }^{2}$, Старинский В.В.1
}

1 ФГБУ «НМИРЦ» Минздрава России

249036, Российская Федерация, Калужская область, г. Обнинск, ул. Королёва, д. 4

${ }_{2}^{2}$ МНИОИ им. П.А. Герцена - филиал ФГБУ «НМИРЦ» Минздрава России

125284, Российская Федерация, г. Москва, 2-ой Боткинский проезд, дом 3

\section{Резюме:}

Представлен краткий обзор основных инновационных научных исследований, проводимых в МНИОИ им. П.А. Герцена за последнее десятилетие, и результаты их внедрения в клиническую практику. На основе 36 патентов РФ на изобретение разработаны новые медицинские технологии диагностики, лечения и реабилитации онкологических пациентов, разрешение на клиническое применение которых на территории Российской Федерации выдано Федеральной службой по надзору в сфере здравоохранения и социального развития.

\section{REALIZATION OF RESULTS OF INNOVATIONAL RESEARCH IN CLINICAL ONCOLOGICAL}

Kaprin A.D. ${ }^{1}$, Alexandrova L.M. ${ }^{2}$, Starinskiy V.V. ${ }^{1}$

'NMRRC

Ulitsa Korolyeva, d. 4, Oblinsk, Kaluzskaya Oblast', 249036, Russia

${ }^{2}$ P. Hertsen MORI

2-y Botkinskiy proezd, 3, Moskva, 125284, Russia

\section{Abstract:}

We present a brief overview of major innovative scientific research conducted at the research oncological Institute n. a. P. A. Herzen over the last decade, and the results of their the introduction into clinical practice.

On the basis of 36 patents of the for the invention in Russian Federation we developed new medical technologies for diagnosis, treatment and rehabilitation of cancer patients, permission for clinical use in the territory of the Russian Federation issued by the Federal service on surveillance in healthcare and social development.

Одним из важных направлений деятельности научно-исследовательской организации является инновационная деятельность, в результате которой рождаются новые идеи, новые и усовершенствованные продукты, новые или усовершенствованные технологии. Результаты инновационной деятельности, являющиеся интеллектуальной собственностью, выражаются в виде инновационной продукции. При этом последняя может иметь как конкретную вещественную, так и неовеществленную форму, например, ноу-хау.

Юридическое понятие «интеллектуальная собственность» предусмотрено Конвенцией, учредившей в 1967 г. Всемирную организацию интеллектуальной собственности, главной задачей которой является содействие охране интеллектуальной собственности [1].

Исторически возникновение правового регулирования интеллектуальной собственности на международном уровне связано с Парижской конвенцией 1883 г. по охране промышленной собственности, регулированию использования патентов, товарных названий и прочее, в том числе и мерам по наказанию 
за их незаконное использование. Право на интеллектуальную собственность определено в III Международном пакте об экономических, социальных и культурных правах [2]. 1 июля 1965 г. с целью обеспечения защиты отечественного приоритета на изобретения к Парижской конвенции присоединился и СССР. Существующее законодательство Российской Федерации отражает содержание и направленность большинства международных правовых актов в этой области.

В России законодательная охрана интеллектуальной собственности гарантирована 44 статьей Конституции Российской Федерации, а также федеральными нормативноправовыми актами в области охраны прав на объекты интеллектуальной собственности [3]. Вопросы патентной защиты регулируются Российским патентным ведомством (Роспатентом) в соответствии с частью четвертой Гражданского кодекса РФ (раздел VII, глава 72) [4]. Патентная форма защиты обеспечивает исключительные права на изобретения, полезные модели на территории РФ, удостоверенные патентами, выданными федеральным органом исполнительной власти по интеллектуальной собственности, позволяет развивать лицензионную торговлю технической документацией, новейшими технологиями. Право на использование изобретения, товарного знака и других результатов инновационной деятельности передается путем заключения лицензионного соглашения. Лицензия представляет собой разрешение отдельным лицам (физическим или юридическим) использовать изобретение, защищенное патентом, технические знания, товарный знак и т. д. Объекты интеллектуальной собственности включаются в состав нематериальных активов предприятий и могут приносить существенный доход.

В МНИОИ им. П.А. Герцена значительная доля научно-исследовательских работ выполняется на уровне изобретений, то есть отвечает условиям патентоспособности: новизне, изобретательскому уровню, промышленная применимости.

Одним из приоритетных направлений развития клинической онкологии является разработка методик фотодинамической терапии (ФДТ) и флюоресцентной диагностики злокачественных опухолей, фотосенсибилизаторов нового поколения. В России МНИОИ им. П.А. Герцена является лидером в продвижении этого направления. В настоящее время продолжается активная деятельность как по внедрению новых разработок в практическое здравоохранение различных территорий страны, так и по усовершенствованию вариантов лечения опухолей различной локализации. Разработана и защищена серия новых технологий ФДТ, в том числе: способ лечения поверхностного рака мочевого пузыря [5], способ интраоперационной фотодинамической терапии при опухолевом поражении плевры [6], способ консервативного лечения и профилактики рецидивов вирус-ассоциированного предрака и раннего рака шейки матки [7], устройство для проведения внутритканевой лазерной гипертермии и фотодинамической терапии и способ их осуществления [8], способ интраоперационной фотодинамической терапии брюшины и устройство для его осуществления [9], способ модификации фотодинамического лечения [10], способ интраоперационной флюоресцентной диагностики метастатического пораже- ния лимфатических узлов [11]. Развитие этого направления позволяет достоверно оценить площадь опухолевого поражения в результате выявления скрытых форм рака, провести органосохраняющее функционально-щадящее лечение больных, в том числе и функционально неоперабельных, способствует улучшению качества их жизни.

Научные сотрудники института принимают активное участие в разработке фотосенсибилизаторов нового поколения и методик их использования. Исследования проводятся преимущественно совместно с ФГУП «ГНЦ «НИОПИК» (генеральный директор, член-корреспондент РАН Г.Н. Ворожцов). К числу таких разработок относится блок патентов на способы подавления роста опухолей [12-14], композиция для флюоресцентной диагностики [15], фотосенсибилизаторы для фотодинамической терапии [16-18]. Патент № 2339414 на изобретение «Способ подавления роста опухоли», существенными признаками которого являются внутривенное введение наночастиц фталоцианинов с последующим облучением опухоли лазерными импульсами с длиной волны в области интенсивного поглощения наночастиц, внесен в российский реестр 100 лучших изобретений 2008 года [12].

В последнее десятилетие отмечается тенденция к росту заболеваемости раком гортани преимущественно мужского населения страны. При этом у значительной части больных новообразования выявляются в запущенной стадии, когда процесс рассматривается как неоперабельный, или хирургическое вмешательство зачастую приводит к формированию выраженных анатомо-функциональных дефектов соседних органов и тканей. На этапе хирургического лечения пациентов с рецидивными местно-распространенными опухолями гортани и гортаноглотки, поражающими трахею, в институте используется способ формирования загрудинной трахеостомы при расположении резецированного края трахеи в переднем средостении [19]. Кольцо трахеостомы создается в результате парциальной резекции рукоятки грудины и формирования мостовидного кожно-фасциального лоскута на грудной стенке. Технология позволяет выполнить хирургическое лечение больным, ранее считавшимся неоперабельными, избежать возможных осложнений во время операции и в раннем послеоперационном периоде, обеспечить 3-х и 5-летнюю выживаемость, создать условия для улучшения качества жизни этой сложной категории пациентов.

С целью выполнения оперативных вмешательств на гортани перорально, бескровно, прецизионно, атравматично с минимальными реактивными явлениями в послеоперационном периоде сконструирован электрод [20]. Рабочее окончание изделия имеет особую форму, позволяющую не вводить электрод внутрь ткани, огибать мешающие воздействию анатомические структуры, не травмировать здоровые ткани. При этом глубина воздействия ограничивается, как и требуется при вмешательствах на гортани, 5-7 мм, что уменьшает интраоперационную травму и снижает риск послеоперационных осложнений.

После ларингоэктомии по поводу рака важнейшим этапом является восстановление у больного голосовой функции. В последние годы широкое распространение получило восстановление голосовой функции после 
удаления гортани с помощью голосовых протезов, при этом конструкция трахеостомы имеет большое значение в осуществлении функций дыхания и голосообразования в послеоперационном периоде. Создание бесканюльной трахеостомы стабильного, адекватного размера (от 0,5 до 2 см) является актуальной задачей. В институте разработан и внедрен в клиническую практику способ восстановления голосовой функции после ларингэктомии, включающий трахеопищеводное шунтирование с эндопротезированием и формированием бесканюльной трахеостомы [21]. Новая медицинская технология позволяет создать широкую стабильную трахеостому, обеспечивающую свободное дыхание и пригодную для восстановления голосовой функции у безгортанных больных с помощью голосовых протезов, что исключает пользование трахеотомической трубкой и улучшает качество жизни.

Современный этап развития клинической онкологии характеризуется разработкой подходов к органосохраняющему и функционально щадящему лечению. В институте разработан способ первичного органосохраняющего лечения инвазивного рака шейки матки, включающий радикальную трахелэктомию абдоминальным доступом с сохранением матки и ее восходящих артериальных и венозных кровеносных сосудов [22]. Оперативное вмешательство в данном объеме позволяет сохранить детородную функцию, является адекватной альтернативой расширенной экстирпации матки у пациенток репродуктивного возраста.

Органосохраняющее лечение начального рака молочной железы включает на сегодняшний день радикальные резекции из одного или двух кожных доступов (подмышечного и параареолярного), радикальные резекции с пластикой фрагментом широчайшей мышцы спины, радикальные резекции с одномоментной реконструкцией силиконовым эндопротезом или тканевым экспандером, субтотальные радикальные резекции с перемещением фрагмента проксимального отдела прямой мышцы живота. Перечисленные выше методики подразумевают удаление в едином блоке опухоли, фрагмента собственной фасции большой грудной мышцы, подмышечной, подлопаточной и подключичной клетчатки с лимфатическими узлами, последующим замещением железистой ткани железы иным материалом (жировая ткань, мышца, силиконовый эндопротез), сводя к минимуму манипуляции на оставшейся железистой ткани.

В МНИОИ им. П.А. Герцена активно развивается новое направление в онкологии - онкопластическая хирургия. При лечении больных раком молочной железы широко применяются новые технологии хирургического пособия [23-26]. Изобретения направлены на улучшение эффекта реконструктивной и пластической хирургии молочной железы. Использование их в клинической практике позволяет улучшить эстетические результаты реконструктивно-пластической операции, в различные сроки послеоперационного периода предупредить развитие возможных осложнений, таких как пролежни кожи, пролабирование, выпадение или миграция эндопротеза.

С целью реабилитации онкологических и травматологических больных при закрытии дефектов проксимального отдела пищеварительного тракта (полости рта, глотки и пищевода) применяется способ формирования тонкокишечно-брыжеечного аутотрансплантата. Аутотрансплантат формируется из аутологичных донорских тканей и содержит не только слизистую оболочку для реконструкции глотки, шейного отдела пищевода, но и достаточный объем пластического материала для восстановления мягких тканей шеи с изоляцией анатомических структур $[27,28]$.

При реконструктивно-пластической хирургии челюстно-лицевой области, в частности, после радикального удаления опухолей, восстановление тела и центрального отдела альвеолярного отростка нижней челюсти выполняют путем замещения дефекта с помощью составного кожно-мышечно-реберно-лопаточного аутотрансплантата на единых питающих сосудах. Способ позволяет восстановить альвеолярный отросток необходимой высоты для последующей остеоинтеграции дентальных имплантов и зубного протезирования [29].

С целью ускорения регенерации костной ткани при реконструктивной хирургии на костных структурах челюстно-лицевой зоны и опорно-двигательной системы остеосинтез в области резекции костных фрагментов осуществляют посредством титановых пластин для остеосинтеза с многофункциональным биоактивным наноструктурным покрытием (ТУ 9438-003-11458417-2004). Техническим результатом разработанного способа является снижение количества послеоперационных осложнений и ускорение регенерации костной ткани в области остеосинтеза при обширных хирургических вмешательствах у пациентов, имеющих снижение регенераторных свойств костной ткани: у онкологических больных, ранее проходивших курсы полихимиотерапии и лучевой терапии; а также при выраженных воспалительных и травматических поражениях опорно-двигательной системы. Технология обеспечивает предотвращение иммунных реакций отторжения трансплантата, надежную фиксацию имплантата и стабильность костных структур в зоне остеосинтеза, позволяет избежать трудностей, связанных с культивированием стромальных клеток [30].

Важным направлением инновационной деятельности МНИОИ им. П.А. Герцена является разработка новых конструктивных материалов для замещения костных дефектов, их экспериментальное апробирование и внедрение методик лечения в клинику. Совместно с Институтом металлургии и материаловедения им. А. А. Байкова РАН были созданы и защищены патентами РФ следующие композиционные материалы: материал для закрытия костных дефектов при реконструктивно-пластических операциях, представляющий собой частицы карбонатзамещенного гидроксиапатита, выполненные в форме пористых сферических гранул [31]. Материал обладает следующими свойствами: высокая адгезия по отношению к клеткам, сочетание свойств остеокондуктивности и остеоиндуктивности, близость химического и фазового состава имплантируемого материала к составу замещаемой ткани, регулируемость скорости растворения при его замещении костной тканью, возможность трехмерного равномерного заполнения костного дефекта, повторяющего его форму. Материал также может быть насыщен аутологичными мезенхимальными стволовыми клетками 
[32]. Для заполнения костных дефектов при реконструктивно-пластических операциях созданы композитный материал на основе гидроксиапатита и карбоната кальция [33], пористый синтетический коралл [34] и пористые композиционные материалы на основе хитозана [35].

К числу оригинальных перспективных композиционных материалов для замещения костного дефекта относится биоинженерная конструкция, представляющая собой фрагмент коралла, смоделированный в соответствии с формой и величиной замещаемого дефекта и содержащий на поверхности иммобилизованные аутологичные мультипотентные мезенхимальные стромальные клетки [36]. Замещение костного дефекта с использованием данной конструкции успешно апробировано на экспериментальных моделях.

Наряду с разработкой новых способов хирургического лечения злокачественных опухолей большое внимание уделяется способам профилактики и прогнозирования послеоперационных осложнений. В частности, способы профилактики лимфореи после радикальной мастэктомии защищены блоком патентов на изобретение "Способ профилактики лимфореи» [37-39]. Использование разработанных профилактических технологий в клинической практике позволяет уменьшить объем и длительность лимфореи, предотвратить образование лимфоцеле в подмышечной области, ранние раневые осложнения, развитие выраженных рубцовых изменений, постмастэктомического отека верхней конечности, сократить сроки социально-трудовой реабилитации больных.

С целью эвакуации скопившейся лимфы после радикальной мастэктомии разработано устройство для повторного дренирования подмышечной области [40]. Устройство позволяет достичь нескольких лечебных результатов: минимизации травматизации тканей, возможности дренирования без местной анестезии и без дополнительного разреза, асептичности процедуры.

Для профилактики и лечения вторичных онкогинекологических или онкоурологических послеоперационных осложнений, причиной которых является образование лимфатических кист разработана технология их диагностирования с использованием ультразвуковых волн. Способ позволяет выбрать оптимальную тактику ведения больных, расширить области возможного выявления лимфоцеле [41].

у больных с опухолевым поражением легкого используется технология прогнозирования послеоперационных гнойно-воспалительных осложнений, в основе которой лежит иммунологический анализ образцов крови [42]. Авторами изобретения установлено, что прогностическая эффективность известных лабораторных тестов в отношении развития послеоперационных гнойно-воспалительных осложнений у больных с опухолевым поражением легкого может быть существенно повышена путем проведения дифференцированного анализа показателей систем естественной резистентности в зависимости от количества и состава лейкоцитов периферической крови, а также путем определения содержания в сыворотке крови высокомолекулярного гликопротеида муцина MUC1, также известного как CA15-3, CA27.29, KL-6, и анти-MUC1 AAT.
Способ профилактики рецидивов может быть использован при хирургическом лечении злокачественных опухолей органов малого таза, а также при местно-распространенных опухолях забрюшинного пространства или при выполнении расширенных комбинированных оперативных вмешательств [43]. Методика основана на локальном облучении ложа удаленной опухоли или органа с опухолью, моделировании необходимой площади и конфигурации поля облучения, экранировании петель тонкой кишки, толстой кишки, желудка и магистральных сосудов с помощью увлажненного операционного белья. Это позволяет повысить дозу лазерного облучения до 840-1710 Дж, что, в свою очередь, способствует повышению противоопухолевой эффективности фотодинамической терапии и снижению частоты возникновения местного рецидива заболевания в результате подавления возможных субклинических зачатков опухоли.

Для профилактики и коррекции критической брадикардии и других нарушений сердечного ритма и проводимости у онкологических больных с тяжелыми сердечно-сосудистыми заболеваниями разработаны способ профилактики интра- и послеоперационных осложнений, включающий методы временной электрокардиостимуляции - чреспищеводной электростимуляции предсердий или внутрисердечной электрокардиостимуляции [44] и способ оценки риска развития периоперационных сердечно-сосудистых осложнений при внесердечных хирургических вмешательствах [45]. Технологии позволяют снизить операционно-анестезиологический риск путем оптимизации предоперационной диагностики, медикаментозной подготовки и дифференцированного интра- и послеоперационного использования немедикаментозных электрокардиостимуляционных методов профилактики, устранения опасных нарушений сердечного ритма и проводимости в случае неэффективности их медикаментозной коррекции. Разработанный алгоритм ведения этого тяжелого контингента больных позволяет снизить частоту развития периоперационных сердечнососудистых осложнений в 2 раза, в том числе инфаркта миокарда в 5 раз, а летальность от них - в 10 раз.

На решение задачи снижения риска развития послеоперационных диспепсических расстройств, у пациенток онкогинекологического профиля направлена разработка оптимальной интраоперационной лекарственной схемы, включающей использование комбинации ондансетрона, клонидина и дексаметазона с антиэметогенными компонентами анестезии. Технология позволила повысить комфортность и безопасность раннего послеоперационного периода у пациенток с высоким риском развития послеоперационных тошноты и рвоты за счет снижения их частоты до 14,6\% [46].

Разработаны способы профилактики и лечения энтеропатий, развивающихся на фоне полихимиотерапии [47], и послеоперационного болевого синдрома при обширных торакоабдоминальных операциях [48].

Развившийся фантомный болевой синдром, часто отягощенный мучительными расстройствами разных видов чувствительности в несуществующей части конечности, приводит, наряду с физической инвалидизацией, к резкому снижению качества жизни и к социальной дез- 
адаптации пациента из-за присоединяющихся психологических расстройств: стресс, страх, тревога, депрессия, хроническая бессонница; создает препятствия к протезированию утраченной конечности. Особенно выражены и часто проявляются симптомы фантомного болевого синдрома после ампутации по поводу злокачественных опухолей. С целью предотвращения его развития и рецидивирования разработан способ предотвращения фантомного болевого синдрома после ампутации конечностей [49]. Методика включает комплексную пред-, интра- и продленную послеоперационную лекарственную профилактику, полностью предотвращает развитие фантомного болевого синдрома, связанные с ним физические страдания и психологический стресс, облегчает приспособление инвалида к дальнейшей жизни и социально полезной деятельности.

Большое внимание в научной тематике института уделяется проблеме диагностики злокачественных новобразований. Разработаны способы дифференциальной диагностики патологических объемных образований в корне брыжейки тонкой кишки и/или в большом сальнике [50], прогнозирования опухолевых заболеваний молочной железы [51], формирования группы риска по опухолевой патологии молочной железы [52]. Оценку вероятности наличия опухолевых заболеваний молочной железы, осуществляют с применением высокоэффективной жидкостной хроматографии пробы мочи путем идентификации и количественного определения содержания нуклеозидов и расчета прогнозирующей функции. Последние два изобретения созданы в результате научного сотрудничества с коллективами МНКЦ «Интермедбиофизхим», химического факультета МГУ, Института проблем передачи информации им. А. А. Харкевича РАН.

С целью повышения достоверности выявления опухолевых клеток, точности и воспроизводимости измерений разработан способ цитологической диагностики рака методом когерентной фазовой микроскопии [53]. При исследовании неокрашенных, неактивированных живых клеток в автоматическом режиме определяют интенсивность и спектральные характеристики флюктуаций фазовой толщины ядрышек клеток и, при нахождении изучаемых параметров в частотном диапазоне от 0,8 до 20,0 Гц, диагностируют присутствие в препарате клеток рака. Для исследования используется отечественный аппаратно-программный комплекс для морфометрии клеток крови КМКК-01 «Гранат-Гемо» производства ГОУ ВПО «МГТУ им. Н. Э. Баумана».

Актуальным является поиск дополнительных методов, которые позволили бы повысить эффективность цитологической диагностики предопухолевых нарушений и злокачественной патологии в цервикальном эпителии. В настоящее время в качестве дополнительных методов используют иммуноцитохимическое окрашивание клеток цервикального эпителия. Для идентификации клеток используют моноклональные антитела к различным биологическим маркерам, продуцируемым эпителиальными клетками, экспрессия которых зависит от дифференцировки и пролиферативной активности клеток и повышена при неопластических изменениях. Разработана методика формирования группы риска по неопластическим нарушени- ям в эпителии шейки матки, осуществляемая путем иммунофлюоресцентного окрашивания мазка цервикального эпителия с применением моноклонального антитела ИКО 25, взаимодействующего с высокомолекулярным гликопротеидом MUCl, и последующим докрашиванием клеток хромогенным ядерным красителем [54]. Особенности иммуноцитохимического окрашивания клеток цервикального эпителия с ИКО25 служат для выявления пула недифференцированных клеток с патологическими изменениями.

Список разработок МНИОИ им. П. А. Герцена, выполненных на уровне изобретений, может быть дополнен работами, посвященными методике определения алгоритма ведения больного, например, способ прогнозирования послеоперационных осложнений у онкологических больных [55].

Для оценки эффективности консервативной противоопухолевой терапии разработан способ, включающий эхографическое исследование с использованием трехмерной реконструкции области опухолевого поражения [56]. При исследовании определяют объем опухоли, суммарный объем питающих кровеносных сосудов и коэффициент ее васкуляризации до и после лечения. Технология позволяет повысить точность дооперационной диагностики, планировать объем хирургического вмешательства, в том числе органосохраняющих и реконструктивно-пластических операций, и оценить эффективность специфической консервативной терапии. Усиление васкуляризации опухоли после лечения свидетельствует о прогрессировании опухолевого процесса. С использованием компьютерных технологий разработан способ оценки степени васкуляризации опухолевой ткани [57]. Технология морфологического исследования включает использование нового способа количественной оценки васкуляризации для определения биологических свойств злокачественных новообразований. Методика позволяет определять один из показателей метастатического потенциала эпителиальных опухолей и учитывать этот показатель для назначения таргетной терапии, что способствует оптимизации тактики лечения пациента.

Инновационная деятельность МНИОИ им. П. А. Герцена осуществляется в тесном сотрудничестве со многими учреждениями науки, в числе которых такие ведущие отраслевые центры как: ФГУП «ГНЦ «НИОПИК», ФГБОУ ВПО «Московский государственный университет информационных технологий, радиотехники и электроники» (МИРЭА), Институт металлургии и материаловедения им. А. А. Байкова РАН, МГУ им. М.В.Ломоносова, Институт проблем передачи информации им. А.А. Харкевича РАН, ФГУ «Научно-клинический центр оториноларингологии ФМБА», ФГБНУ «НИИ нейрохирургии им. акад. Н.Н. Бурденко». Совместные научные исследования разнопрофильных специалистов по проблеме диагностики и лечения злокачественных новообразований позволяют создавать новейшие высокотехнологичные методики медицинской помощи больным. На основе 36 патентов разработаны новые медицинские технологии диагностики и лечения онкологической патологии, разрешение на клиническое применение которых на территории Российской Федерации выдано Федеральной службой по надзору в сфере здравоохранения и социального развития. 
1. Всемирная организация интеллектуальной собственноcти. URL: http://www.wipo.int/portal/ru/. Дата обращения: 17.04.2015

2. Парижская конвенция по охране промышленной собственности. URL: http://www.wipo.int/treaties/ru/ip/paris/. Дата обращения: 17.04.2015

3. Конституция Российской Федерации. Принята референдумом 12.12.1993. Ред. от 30.12.2008. URL: http://zakonbase. ru/content/part/12808. Дата обращения: 17.04.2015

4. Гражданский кодекс Российской Федерации. Часть четвертая. Раздел VII. Права на результаты интеллектуальной деятельности и средства индивидуализаци. Глава 72. Патентное право. Система ГАРАНТ: URL: http://base.garant.ru/10164072/ 73/\#ixzz3ZzhFYsNy. Дата обращения: 17.04.2015

5. Патент РФ на изобретение № 2346657/20.02.2009. Чиссов В.И., Филоненко Е.В., Теплов А.А., Сидоров Д.В., Соколов В.В., Русаков И.Г. Способ лечения поверхностного рака мочевого пузыря. Доступно по: URL: http://www.freepatent. ru/patents/2346657. Дата обращения: 13.05.2015.

6. Патент РФ на изобретение № 2391907/20.06.2010. Чиссов В.И., Филоненко Е.В., Пикин О.В., Вурсол Д.А., Мироненко Д.Е. Способ интраоперационной фотодинамической терапии при опухолевом поражении плевры. Доступно по: URL: http://www.freepatent.ru/patents/2391907. Дата обращения: 13.05.2015.

7. Патент РФ на изобретение № 2394616/20.07.2010. Чиссов В.И., Новикова Е.Г., Трушина О.И., Соколов В.В., Филоненко Е. В. Способ консервативного лечения и профилактики рецидивов вирус-ассоциированного предрака и раннего рака шейки матки. Доступно по: URL: http://www.freepatent. ru/patents/2394616. Дата обращения: 13.05.2015.

8. Патент РФ на изобретение № 2424009/20.07.2011. Курлов В.Н., Лощенов В.Б., Савельева Т.А., Соколов В.В., Филинов В.Л., Филоненко Е.В., Шевчик С.А., Шикунова И.А., Окушко А. Н. Устройство для проведения внутритканевой лазерной гипертермии и фотодинамической терапии и способ их осуществления. Доступно по: URL: http://www.freepatent. ru/patents/2424009. Дата обращения: 13.05.2015.

9. Патент РФ на изобретение № 2449819/10.05.2012. Чиссов В.И., Филоненко Е.В., Гришин Н.А., Вашакмадзе Л.А., Бутенко А.В., Хомяков В.М., Лукин В.В., Кириллов Н.В., Сидоров Д.В., Ложкин М.В., Петров Л.О. Способ интраоперационной фотодинамической терапии брюшины. Доступно по: URL: http://www.freepatent.ru/patents/2449819. Дата обращения: 13.05.2015.

10. Патент РФ на изобретение № 2449821/10.05.2012. Якубовская Р.И., Воронцова М.С., Кармакова Т.А., Венедиктова Ю.Б., Лукъянец Е.А. Способ модификации фотодинамического лечения. Доступно по: URL: http://www.freepatent. ru/patents/2449821. Дата обращения: 13.05.2015.

11. Патент РФ на изобретение № 2464975/27.10.2012. Филоненко Е.В., Пак Д.Д., Барсамян Г.С. Способ интраоперационной флюоресцентной диагностики метастатического поражения лимфатических узлов. Доступно по: URL: http://www. freepatent.ru/patents/2464975. Дата обращения: 13.05.2015.

12. Патент РФ на изобретение № 2339414/27.11.2008. Коган Б.Я., Бутенин А.В., Ворожцов Г.Н., З Золотавкина Ю.Б., Лукъянец Е.А., Негримовский В.М., Панкратов А.А., Пучкова В.А., Фейзулова Р.К. Чиссов В.И., Якубовская Р.И. Способ подавления роста опухолей. Доступно по: URL: http://www. freepatent.ru/patents/2339414. Дата обращения: 13.05.2015.

13. Патент РФ на изобретение № 2376999/27.12.2009. Бутенин А.В., Ворожцов Г.Н., З Золотавкина Ю.Б., Калия О.Л., Коган Б.Я., Лужков Ю. М., Панкратов А.А., Чиссов В.И., Якубовская Р.И. Способ подавления роста опухолей. Доступно по: URL: http://www.freepatent.ru/patents/2376999. Дата обращения: 13.05.2015.
14. Патент РФ на изобретение № 2392935/27.06.2008. Якубовская Р.И., Немцова Е.Р., Безбородова О.А., Калия О.Л., Ворожцов Г.Н. Способ сочетанного консервативного воздействия на злокачественные опухоли. Доступно по: URL: http://www.freepatent.ru/patents/2392935. Дата обращения: 13.05.2015.

15. Патент РФ на изобретение № 2379026/20.01.2010. Ворожцов Г.Н., Дорожкина Г.Н., Казачкина Н.И., Кузьмин С.Г., Лукъянец С.А., Негримовский В.М., Осиков Н.В., Панкратов А.А., Сахарова Н.А., Чиссов В.И., Якубовская Р.И., Враменко Г.В. Композиция для флуоресцентной диагностики и фотодинамической терапии. Доступно по: URL: http://www. freepatent.ru/patents/2379026. Дата обращения: 13.05.2015.

16. Патент РФ на изобретение № 2479585/20.04.2013. Дудкин С.В., Игнатова А.А., Кобзева Е.С., Лужков Ю.М., Лукъянец Е.А., Макарова Е.А., Морозова Н.Б., Плютинская А.Д., Феофанов А.В., Сахарова Н.А., Чиссов В.И., Якубовская Р.И. Фотосенсибилизатор для фотодинамической терапии. Доступно по: URL: http://www.freepatent. ru/patents/2479585. Дата обращения: 13.05.2015.

17. Патент РФ на изобретение № 2476218/27.02.2013. Дудкин С. В., Ефременко А. В., Игнатова А. А., Кобзева Е. С., Лукъянец Е.А., Макарова Е.А., Морозова Н.Б., Плютинская А.Д., Феофанов А.В., Чиссов В.И., Якубовская Р.И. Фотосенсибилизаторы для фотодинамической терапии. Доступно по: URL: http://www.freepatent.ru/patents/2476218. Дата обращения: 13.05.2015.

18. Патент РФ на изобретение № 2521327/27.06.2014. Чиссов В.И., Якубовская Р. И., Миронов А. Ф., Грин М.А., Плотникова Е. А., Морозова Н. Б., Цыганков А. А. Препарат для фотодинамической терапии и способ фотодинамической терапии рака с его использованием. Доступно по: URL: http://www. freepatent.ru/patents/2521327. Дата обращения: 13.05.2015.

19. Патент РФ на изобретение № 2312626/20.12.2007. Чиссов В.И., Решетов И.В., Трофимов Е.И., Фуки Е.М. Способ формирования загрудинной трахеостомы. Доступно по: URL: http://www.freepatent.ru/patents/2312626. Дата обращения: 13.05.2015.

20. Патент РФ на полезную модель № 154127. Гащенко А.Д., Пономарев В.В., Шевалгин А.А., Кудрин К. Г., Маторин О. В., Макаров В.Н., Решетов И.В. Электрод для пероральных вмешательств. Доступно по: URL: http://poleznayamodel. ru/model/14/145127.html. Дата обращения: 13.05.2015.

21. Патент РФ на изобретение № 2302824/20.07.2007. Ольшанский В.О., Решетов И.В., Новожилова Е.Н., Филюшин М.М. Способ формирования бесканюльной трахеостомы. Доступно по: URL: http://www.freepatent. ru/patents/2302824. Дата обращения: 13.05.2015.

22. Патент РФ на изобретение № 2343859/20.01.2009. Новикова Е. Г., Антипов В.А., Ронина Е.А., Шевчук А.С. Способ первичного органосохраняющего лечения инвазивного рака шейки матки. Доступно по: URL: http://bd.patent. su/2343000-2343999/pat/servl/servlet4fd6.html. Дата обращения: 13.05.2015.

23. Патент РФ на изобретение № 2416370/20.04.2011. Пак Д.Д., Сарибекян Э. К. Способ пластики молочной железы. Доступно по: URL: http://www.freepatent.ru/patents/2416370. Дата обращения: 13.05.2015.

24. Патент РФ на изобретение № 2444310/10.03.2012. Пак Д.Д., Рассказова Е.А., Трошенков Е.А. Способ реконструкции молочной железы после радикальной подкожной мастэктомии. Доступно по: URL: http://www.freepatent.ru/patents/2444310. Дата обращения: 13.05.2015.

25. Патент РФ на изобретение № 2479267/20.04.2013. Волченко А.А., Пак Д.Д. Способ органосохраняющего лечения рака молочной железы. Доступно по: URL: http://www.freepatent. ru/patents/2479267. Дата обращения: 13.05.2015. 
26. Патент РФ на изобретение № 2481075/10.05.2013. Волченко А. А., Пак Д.Д. Способ органосохраняющего лечения рака молочной железы. Доступно по: URL: http://www.freepatent. ru/patents/2481075. Дата обращения: 14.05.2015.

27. Патент РФ на изобретение № 2426503/20.08.2011. Кравцов С.А., Решетов И.В., Чиссов В.И., Ратушный М.В. Способ формирования тонкокишечно-брыжеечного аутотрансплантата. Доступно по: URL: http://www.freepatent. ru/patents/2426503. Дата обращения: 14.05.2015.

28. Патент РФ на изобретение № 2427339/27.08.2011. Кравцов С. А., Решетов И. В., Чиссов В.И. Способ фарингопластики в условиях дефицита пластического материала. Доступно по: URL: http://www.freepatent.ru/patents/2427339. Дата обращения: 14.05.2015.

29. Патент РФ на изобретение № 2445932/27.03.2012. Чиссов В.И., Решетов И.В., Поляков А. П. Способ микрохирургической реконструкции центрального отдела нижней челюсти. Доступно по: URL: http://www.freepatent.ru/patents/2445932. Дата обращения: 14.05.2015.

30. Патент РФ на изобретение № 2410050/27.01.2011. Чиссов В.И., Решетов И.В., Филюшин М. М., Ратушный М. В., Сухарев С. С. Способ ускорения регенерации костной ткани при проведении остеосинтеза. Доступно по: URL: http://www. freepatent.ru/patents/2410050. Дата обращения: 12.05.2015.

31. Патент РФ на изобретение № 2333010/10.09.2008. Чиссов В.И., Баринов С. М., Сергеева Н.С., Решетов И. В., Свиридова И. К., Кирсанова В.А., Фадеева И. В., Комлев В. С., Ахмедова С.А., Филюшин М.М. Материал для закрытия костных дефектов при реконструктивно-пластических операциях. Доступно по: URL: http://www.freepatent.ru/patents/2333010. Дата обращения: 14.05.2015.

32. Патент РФ на изобретение № 2375007/10.12.2009. Решетов И.В., Чиссов В.И., Филюшин М.М. Способ замещения костных дефектов. Доступно по: URL: http://www.freepatent. ru/patents/2375007. Дата обращения: 14.05.2015.

33. Патент РФ на изобретение № 2429885/27.09.2011. Баринов С.М., Смирнов В.В., Гольдберг М.А., Чиссов В.И., Сергеева Н.С., Свиридова И.К., Кирсанова В.А., Ахмедова С.А. Композиционный материал на основе гидроксиапатита и карбоната кальция для заполнения костных дефектов при реконструктивно-пластических операциях. Доступно по: URL: http://www.freepatent.ru/patents/2429885. Дата обращения: 14.05.2015.

34. Патент РФ на изобретение № 2368354/27.09.2009. Баринов С.М., Смирнов В.В., Комлев В.С., Чиссов В.И., Сергеева Н.С., Свиридова И.К., Кирсанова В.А., Ахмедова С.А. Пористый синтетический коралл для реконструкции костных дефектов и способ его получения. Доступно по: URL: http://www.freepatent.ru/patents/2368354. Дата обращения: 14.05.2015.

35. Патент РФ на изобретение № 237601920.12.2009. Баринов С.М., Смирнов В.В., Федотов А.Ю., Комлев В.С., Фадеева И.В., Сергеева Н.С., Свиридова И.К., Кирсанова В.А., Ахмедова С.А. Пористые композиционные материалы на основе хитозана для заполнения костных дефектов. Доступно по: URL: http://www.freepatent.ru/patents/2376019. Дата обращения: 14.05.2015.

36. Патент РФ на полезную модель № 86455. Агзамов Д.С., Тепляков В.В., Франк Г.А., Ахмедова С.А., Кирсанова В.А., Свиридова И.К., Сергеева Н.С., Чиссов В.И. Биоинженерная конструкция. Доступно по: URL: http://poleznayamodel. ru/model/8/86455.html. Дата обращения: 12.05.2015.

37. Патент РФ на изобретение № 2334485/27.09.2008. Пак Д.Д., Соколов В.В., Кабисов Р.К., Ермощенкова М.А. Способ профилактики лимфореи после радикальной мастэктомии. Доступно по: URL: http://www.freepatent.ru/patents/2334485. Дата обращения: 12.05.2015.

38. Патент РФ на изобретение № 2427333/27.08.2011. Чиссов В.И., Пак Д.Д., Ермощенкова М.А. Способ интраоперационной профилактики лимфореи при радикальной мастэктомии. Доступно по: URL: http://www.freepatent. ru/patents/2427333. Дата обращения: 12.05.2015.

39. Патент РФ на изобретение № 2410034/27.01.2011. Пак Д.Д., Ермощенкова М. В. Способ интраоперационной профилактики лимфореи при радикальной мастэктомии. Доступно по: URL: http://www.freepatent.ru/patents/2410034. Дата обращения: 12.05.2015.

40. Патент РФ на полезную модель № 94461. Усов Ф.Н., Ермощенкова М.В., Пак Д.Д. Устройство для повторного дренирования подмышечной области. Доступно по: URL: http://poleznayamodel.ru/model/9/94461.html. Дата обращения: 12.05.2015.

41. Патент РФ на изобретение № 2414174/20.03.2011. Новикова Е. Г., Степанов С. О., Скрепцова Н. С. Способ профилактики и лечения послеоперационных осложнений. Доступно по: URL: http://www.freepatent.ru/patents/2414174. Дата обращения: 12.05.2015.

42. Патент РФ на изобретение № 2473083/20.01.2013. Якубовская Р.И., Немцова Е.Р., Кармакова Т.А., Скрипник В.В., Пикин О.В., Рудаков Р.В., Амиралиев А.М. Способ прогнозирования послеоперационных осложнений у больных с опухолевым поражением легкого. Доступно по: URL: http://www. freepatent.ru/patents/2473083. Дата обращения: 12.05.2015.

43. Патент РФ на изобретение № 2486933/10.07.2013. Филоненко Е. В., Вашакмадзе Л. А., Черемисов В.В., Теплов А. А., Алексеев Б.Я., Смирнова С. В., Хомяков В. М. Способ профилактики рецидивов при хирургическом лечении злокачественных опухолей малого таза или неорганных опухолей забрюшинного пространства. Доступно по: URL: http://www.freepatent. ru/patents/2486933. Дата обращения: 12.05.2015.

44. Патент РФ на изобретение № 2326704/20.06.2008. Осипова Н.А., Хороненко В.Э. Способ профилактики интра- и послеоперационных сердечно-сосудистых осложнений. Доступно по: URL: http://www.freepatent.ru/patents/2326704. Дата обращения: 12.05.2015.

45. Патент РФ на изобретение № 2410017/27.01.2011. Хороненко В. Э., Осипова Н.А., Лагутин М.Б., Шеметова М.М. Способ оценки риска развития периоперационных сердечнососудистых осложнений при внесердечных хирургических вмешательствах. Доступно по: URL: http://www.freepatent. ru/patents/2410017. Дата обращения: 12.05.2015.

46. Патент РФ на изобретение № 2523565/20.07.2014. Хороненко В.Э., Новикова О.В., Баскаков Д. С. Способ профилактики синдрома послеоперационной тошноты и рвоты в онкогинекологии. Доступно по: URL: http://www.freepatent. ru/patents/2523565. Дата обращения: 12.05.2015.

47. Патент РФ на изобретение № 2405546/10.02.2010. Тюрина Н. Г., Кобзева И. В., Ерастова Е.И., Грачева З.Д. Способ профилактики и лечения энтеропатий, развивающихся на фоне полихимиотерапии. Доступно по: URL: http://www.freepatent. ru/patents/2405546. Дата обращения: 12.05.2015.

48. Патент РФ на изобретение № 2382646/27.02.2010. Осипова Н.А., Петрова В.В., Ластухин А.В., Кудрявцев С. Б. Способ профилактики и лечения послеоперационного болевого синдрома при обширных торакоабдоминальных операциях. Доступно по: URL: http://www.freepatent.ru/patents/2382646. Дата обращения: 12.05.2015.

49. Патент РФ на изобретение № 2446795/10.04.2012. Осипова Н.А., Тепляков В.В., Собченко Л.А., Петрова В.В. Способ предотвращения фантомного болевого синдрома после ампутации конечностей. Доступно по: URL: http://www. freepatent.ru/patents/2446795. Дата обращения: 12.05.2015.

50. Патент РФ на изобретение № 2344762/27.01.2009. Казакевич В.И., Митина Л.А. Способ дифференциальной диагностики патологических объемных образований в корне брыжейки тонкой кишки и/или в большом сальнике. Доступно по: URL: http://www.freepatent.ru/patents/2344762. Дата обращения: 12.05.2015.

51. Патент РФ на изобретение № 2390025/27.12.2009. Хованская Т.П., Чиссов В.И., Юрков Е.Ф., Кузьмин С.Г., Шпак А.В., 
Шпигун О.А., Попик М.В., Сергеева Н.С., Гитис В.Г., Пирогов С.А. Способ прогнозирования опухолевых заболеваний молочной железы. Доступно по: URL: http://www.findpatent. ru/patent/239/2390025.html. Дата обращения: 14.05.2015.

52. Патент РФ на изобретение № 2386968/20.04.2010. Чиссов В.И., ХованскаяТ.П., Сергеева Н.С., Шпигун О.А., Попик М.В., Шпак А.В., Гитис В.Г., Пирогов С.А., Юрков Е.Ф., Кузьмин С.Г. Способ формирования группы риска опухолевой патологии молочной железы. Доступно по: URL: http://www1.fips.ru/fips_servl/fips_servlet?DB=RUPAT\&rn=64 75\&DocNumber=2386968\&TypeFile=html. Дата обращения: 14.05.2015.

53. Патент РФ на изобретение № 2306868/27.09.2007. Чиссов В.И., Решетов И.В., Волченко Н.Н., Славнова Е.Н., Тычинский В.П., К Кретушев А.В., Клемяшов И.В. Способ диагностики рака. Доступно по: URL: http://www.freepatent. ru/patents/2306868. Дата обращения: 14.05.2015.

54. Патент РФ на изобретение № 2437096/20.12.2011. Якубовская Р. И., Кармакова Т. А., Волченко Н.Н., Новикова Е. Г., Трушина О.И. Способ формирования группы риска неопластиче-

\section{References:}

1. World intellectual property organization.. URL: http://www. wipo.int/portal/ru/. Cited 17.04.2015. (In Russ)

2. Paris Convention for the Protection of Industrial Property. URL: http://www.wipo.int/treaties/ru/ip/paris/. Cited 17.04.2015. (In Russ)

3. Konstitutsiya Rossiiskoi Federatsii. Prinyata referendumom 12.12.1993. Red. ot 30.12.2008. URL: http://zakonbase.ru/content/part/12808. Cited 17.04.2015. (In Russ)

4. Grazhdanskii kodeks Rossiiskoi Federatsii. Chast' chetvertaya. Razdel VII. Prava na rezul'taty intellektual'noi deyatel'nosti i sredstva individualizatsi. Glava 72. Patentnoe pravo. Sistema GARANT: URL: http://base.garant.ru/10164072/73/\#ixzz3ZzhFYsNy. Cited 17.04.2015. (In Russ)

5. Patent RF na izobretenie № 2346657/20.02.2009. Chissov V.I., Filonenko E. V., Teplov A.A., Sidorov D.V., Sokolov V.V., Rusakov I.G. Sposob lecheniya poverkhnostnogo raka mochevogo puzyrya. URL: http://www.freepatent.ru/patents/2346657. Cited 13.05.2015. (In Russ)

6. Patent RF na izobretenie № 2391907/20.06.2010. Chissov V.I., Filonenko E. V., Pikin O.V., Vursol D.A., Mironenko D.E. Sposob intraoperatsionnoi fotodinamicheskoi terapii pri opukholevom porazhenii plevry. URL: http://www.freepatent. ru/patents/2391907. Cited 13.05.2015. (In Russ)

7. Patent RF na izobretenie № 2394616/20.07.2010. Chissov V.I., Novikova E. G., Trushina O. I., Sokolov V. V., Filonenko E. V. Sposob konservativnogo lecheniya i profilaktiki retsidivov virus-assotsiirovannogo predraka i rannego raka sheiki matki. URL: http://www.freepatent.ru/patents/2394616. Cited 13.05.2015. (In Russ)

8. Patent RF na izobretenie № 2424009/20.07.2011. Kurlov V. N., Loshchenov V.B., Savel'eva T.A., Sokolov V.V., Filinov V. L., Filonenko E. V., Shevchik S. A., Shikunova I. A., Okushko A. N. Ustroistvo dlya provedeniya vnutritkanevoi lazernoi gipertermii $\mathrm{i}$ fotodinamicheskoi terapii i sposob ikh osushchestvleniya. URL: http://www.freepatent.ru/patents/2424009. Cited 13.05.2015. (In Russ)

9. Patent RF na izobretenie № 2449819/10.05.2012. Chissov V.I. Filonenko E.V., Grishin N.A., Vashakmadze L.A., Butenko A. V., Khomyakov V.M., Lukin V.V., Kirillov N. V., Sidorov D. V., Lozhkin M.V., Petrov L.O. Sposob intraoperatsionnoi fotodinamicheskoi terapii bryushiny. URL: http://www.freepatent.ru/patents/2449819. Cited 13.05.2015. (In Russ)

10. Patent RF na izobretenie № 2449821/10.05.2012. Yakubovskaya R.I., Vorontsova M.S., Karmakova T.A., Venediktova Yu. B., ских нарушений в эпителии шейки матки. Доступно по: URL: http://www.freepatent.ru/patents/2437096. Дата обращения: 14.05.2015.

55. Патент РФ на изобретение патент № 2384297/20.03.2010. Якубовская Р.И., Немцова Е.Р., Кармакова Т.А., Пикин О.В., Вурсол Д.А., Амиралиев А.М. Способ прогнозирования послеоперационных осложнений у онкологических больных. Доступно по: URL: http://www.freepatent.ru/patents/2384297. Дата обращения: 14.05.2015.

56. Патент РФ на изобретение патент № 2305494/10.09.2007. Митина Л.А., Казакевич В.И., Соколов В.В., Романов Д.В., Шумейко А. Э., Филоненко Е. В., Седых С. А. Способ ультразвуковой оценки эффективности консервативной противоопухолевой терапии. Доступно по: URL: http://www.freepatent. ru/patents/2305494. Дата обращения: 14.05.2015.

57. Патент РФ на изобретение патент № 2366951/10.09.2009. Завалишина Л.Э., Андреева Ю. Ю., Франк Г. А., Петров А. Н., Батева М. В. Способ оценки васкуляризации. Доступно по: URL: http://www.freepatent.ru/patents/2366951. Дата обращения: 14.05.2015.
Luk»yanets E. A. Sposob modifikatsii fotodinamicheskogo lecheniya. URL: http://www.freepatent.ru/patents/2449821. Cited 13.05.2015. (In Russ)

11. atent RF na izobretenie № 2464975/27.10.2012. Filonenko E. V., Pak D. D., Barsamyan G.S. Sposob intraoperatsionnoi flyuorestsentnoi diagnostiki metastaticheskogo porazheniya limfaticheskikh uzlov. URL: http://www.freepatent.ru/patents/2464975. Cited 13.05.2015. (In Russ)

12. Patent RF na izobretenie № 2339414/27.11.2008. Kogan B. Ya., Butenin A. V., Vorozhtsov G. N., Zolotavkina Yu. B., Luk»yanets E.A., Negrimovskii V.M., Pankratov A.A., Puchkova V.A., Feizulova R. K. Chissov V.I., Yakubovskaya R.I. Sposob podavleniya rosta opukholei. URL: http://www.freepatent.ru/patents/2339414. Cited 13.05.2015. (In Russ)

13. Patent RF na izobretenie № 2376999/27.12.2009. Butenin A. V., Vorozhtsov G. N., Zolotavkina Yu. B., Kaliya O.L., Kogan B.Ya., Luzhkov Yu.M., Pankratov A.A., Chissov V.I., Yakubovskaya R.I. Sposob podavleniya rosta opukholei. URL: http://www. freepatent.ru/patents/2376999. Cited 13.05.2015. (In Russ)

14. Patent RF na izobretenie № 2392935/27.06.2008. Yakubovskaya R.I., Nemtsova E. R., Bezborodova O.A., Kaliya O. L., Vorozhtsov G. N. Sposob sochetannogo konservativnogo vozdeistviya na zlokachestvennye opukholi. URL: http://www.freepatent. ru/patents/2392935. Cited 13.05.2015. (In Russ)

15. Patent RF na izobretenie № 2379026/20.01.2010. Vorozhtsov G. N., Dorozhkina G. N., Kazachkina N. I., Kuz'min S.G., Luk»yanets S.A., Negrimovskii V.M., Osikov N.V., Pankratov A.A., Sakharova N.A., Chissov V.I., Yakubovskaya R.I., vramenko G.V. Kompozitsiya dlya fluorestsentnoi diagnostiki i fotodinamicheskoi terapii. URL: http://www.freepatent.ru/patents/2379026. Cited 13.05.2015. (In Russ)

16. Patent RF na izobretenie № 2479585/20.04.2013. Dudkin S. V., Ignatova A.A., Kobzeva E.S., Luzhkov Yu. M., Luk»yanets E.A., Makarova E.A., Morozova N.B., Plyutinskaya A.D., Feofanov A. V., Sakharova N.A., Chissov V.I., Yakubovskaya R.I. Fotosensibilizator dlya fotodinamicheskoi terapii. URL: http://www. freepatent.ru/patents/2479585. Cited 13.05.2015. (In Russ)

17. Patent RF na izobretenie № 2476218/27.02.2013. Dudkin S. V., Efremenko A.V., Ignatova A.A., Kobzeva E.S., Luk»yanets E.A., Makarova E.A., Morozova N.B., Plyutinskaya A.D., Feofanov A. V., Chissov V.I., Yakubovskaya R. I. Fotosensibilizatory dlya fotodinamicheskoi terapii. URL: http://www.freepatent.ru/patents/2476218. Cited 13.05.2015. (In Russ)

18. Patent RF na izobretenie № 2521327/27.06.2014. Chissov V.I., 
Yakubovskaya R.I., Mironov A. F., Grin M.A., Plotnikova E.A., Morozova N. B., Tsygankov A. A. Preparat dlya fotodinamicheskoi terapii i sposob fotodinamicheskoi terapii raka s ego ispol'zovaniem. URL: http://www.freepatent.ru/patents/2521327. Cited 13.05.2015. (In Russ)

19. Patent RF na izobretenie № 2312626/20.12.2007. Chissov V.I., Reshetov I.V., Trofimov E.I., Fuki E.M. Sposob formirovaniya zagrudinnoi trakheostomy. URL: http://www.freepatent.ru/patents/2312626. Cited 13.05.2015. (In Russ)

20. Patent RF na poleznuyu model' № 154127. Gashchenko A.D., Ponomarev V. V., Shevalgin A. A., Kudrin K. G., Matorin O. V., Makarov V.N., Reshetov I.V. Elektrod dlya peroral'nykh vmeshatel'stv. URL: http://poleznayamodel.ru/model/14/145127.html. Cited 13.05.2015. (In Russ)

21. Patent RF na izobretenie № 2302824/20.07.2007. Ol'shanskii V. O., Reshetov I. V., Novozhilova E. N., Filyushin M. M. Sposob formirovaniya beskanyul'noi trakheostomy. URL: http://www.freepatent.ru/patents/2302824. Cited 13.05.2015. (In Russ)

22. Patent RF na izobretenie № 2343859/20.01.2009. Novikova E. G., Antipov V. A., Ronina E. A., Shevchuk A. S. Sposob pervichnogo organosokhranyayushchego lecheniya invazivnogo raka sheiki matki. URL: http://bd.patent.su/2343000-2343999/pat/servl/servlet4fd6.html. Cited 13.05.2015. (In Russ)

23. Patent RF na izobretenie № 2416370/20.04.2011. Pak D. D., Saribekyan E. K. Sposob plastiki molochnoi zhelezy. URL: http://www. freepatent.ru/patents/2416370. Cited 13.05.2015. (In Russ)

24. Patent RF na izobretenie № 2444310/10.03.2012. Pak D.D., Rasskazova E.A., TroshenkovE.A. Sposob rekonstruktsii molochnoi zhelezy posle radikal'noi podkozhnoi mastektomii. URL: http://www.freepatent.ru/patents/2444310. Cited 13.05.2015. (In Russ)

25. Patent RF na izobretenie № 2479267/20.04.2013. Volchenko A. A., Pak D.D. Sposob organosokhranyayushchego lecheniya raka molochnoi zhelezy. URL: http://www.freepatent.ru/patents/2479267. Cited 13.05.2015. (In Russ)

26. Patent RF na izobretenie № 2481075/10.05.2013. Volchenko A. A., Pak D. D. Sposob organosokhranyayushchego lecheniya raka molochnoi zhelezy. URL: http://www.freepatent.ru/patents/2481075. Cited 14.05.2015. (In Russ)

27. Patent RF na izobretenie № 2426503/20.08.2011. Kravtsov S. A., Reshetov I. V., Chissov V.I., Ratushnyi M. V. Sposob formirovaniya tonkokishechno-bryzheechnogo autotransplantata. URL: http://www.freepatent.ru/patents/2426503. Cited 14.05.2015. (In Russ)

28. Patent RF na izobretenie № 2427339/27.08.2011. Kravtsov S. A. Reshetov I.V., Chissov V.I. Sposob faringoplastiki v usloviyakh defitsita plasticheskogo materiala. URL: http://www.freepatent. ru/patents/2427339. Cited 14.05.2015. (In Russ)

29. Patent RF na izobretenie № 2445932/27.03.2012. Chissov V.I., Reshetov I. V., Polyakov A. P. Sposob mikrokhirurgicheskoi rekonstruktsii tsentral'nogo otdela nizhnei chelyusti. URL: http://www. freepatent.ru/patents/2445932. Cited 14.05.2015. (In Russ)

30. Patent RF na izobretenie № 2410050/27.01.2011. Chissov V.I., Reshetov I.V., Filyushin M.M., Ratushnyi M.V., Sukharev S.S. Sposob uskoreniya regeneratsii kostnoi tkani pri provedenii osteosinteza. URL: http://www.freepatent.ru/patents/2410050. Cited 12.05.2015. (In Russ)

31. Patent RF na izobretenie № 2333010/10.09.2008. Chissov V.I. Barinov S. M., Sergeeva N.S., Reshetov I. V., Sviridova I. K., Kirsanova V. A., Fadeeva I.V., Komlev V.S., Akhmedova S.A., Filyushin M.M. Material dlya zakrytiya kostnykh defektov pri rekonstruktivno-plasticheskikh operatsiyakh. URL: http://www. freepatent.ru/patents/2333010. Cited 14.05.2015. (In Russ)

32. Patent RF na izobretenie № 2375007/10.12.2009. Reshetov I. V., Chissov V.I., Filyushin M.M. Sposob zameshcheniya kostnykh defektov. URL: http://www.freepatent.ru/patents/2375007. Cited 14.05.2015. (In Russ)

33. Patent RF na izobretenie № 2429885/27.09.2011. Barinov S. M., Smirnov V. V., Gol'dberg M. A., Chissov V.I., Sergeeva N. S., Sviridova I. K., Kirsanova V. A., Akhmedova S. A. Kompozitsionnyi ma- terial na osnove gidroksiapatita i karbonata kal'tsiya dlya zapolneniya kostnykh defektov pri rekonstruktivno-plasticheskikh operatsiyakh. URL: http://www.freepatent.ru/patents/2429885. Cited 14.05.2015. (In Russ)

34. Patent RF na izobretenie № 2368354/27.09.2009. Barinov S. M., Smirnov V. V., Komlev V.S., Chissov V.I., Sergeeva N.S., Sviridova I.K., Kirsanova V.A., Akhmedova S.A. Poristyi sinteticheskii korall dlya rekonstruktsii kostnykh defektov i sposob ego polucheniya. URL: http://www.freepatent.ru/patents/2368354. Cited 14.05.2015. (In Russ)

35. Patent RF na izobretenie № 237601920.12.2009. Barinov S. M., Smirnov V. V., Fedotov A.Yu., Komlev V.S., Fadeeva I. V., Sergeeva N.S., Sviridova I. K., Kirsanova V. A., Akhmedova S. A. Poristye kompozitsionnye materialy na osnove khitozana dlya zapolneniya kostnykh defektov. URL: http://www.freepatent.ru/patents/2376019. Cited 14.05.2015. (In Russ)

36. Patent RF na poleznuyu model' № 86455. Agzamov D. S., Teplyakov V.V., Frank G.A., Akhmedova S. A., Kirsanova V.A., Sviridova I. K., Sergeeva N.S., Chissov V. I. Bioinzhenernaya konstruktsiya. URL: http://poleznayamodel.ru/model/8/86455.html. Cited 12.05.2015. (In Russ)

37. Patent RF na izobretenie № 2334485/27.09.2008. Pak D.D., Sokolov V.V., Kabisov R. K., Ermoshchenkova M. A. Sposob profilaktiki limforei posle radikal'noi mastektomii. URL: http://www. freepatent.ru/patents/2334485. Cited 12.05.2015. (In Russ)

38. Patent RF na izobretenie № 2427333/27.08.2011. Chissov V.I., Pak D. D., Ermoshchenkova M. A. Sposob intraoperatsionnoi profilaktiki limforei pri radikal'noi mastektomii. URL: http://www. freepatent.ru/patents/2427333. Cited 12.05.2015. (In Russ)

39. Patent RF na izobretenie № 2410034/27.01.2011. Pak D. D., Ermoshchenkova M. V. Sposob intraoperatsionnoi profilaktiki limforei pri radikal'noi mastektomii. URL: http://www.freepatent. ru/patents/2410034. Cited 12.05.2015. (In Russ)

40. Patent RF na poleznuyu model' № 94461. Usov F. N., Ermoshchenkova M.V., Pak D.D. Ustroistvo dlya povtornogo drenirovaniya podmyshechnoi oblasti. URL: http://poleznayamodel. ru/model/9/94461.html. Cited 12.05.2015. (In Russ)

41. Patent RF na izobretenie № 2414174/20.03.2011. Novikova E. G., Stepanov S.O., Skreptsova N.S. Sposob profilaktiki i lecheniya posleoperatsionnykh oslozhnenii. URL: http://www.freepatent. ru/patents/2414174. Cited 12.05.2015. (In Russ)

42. Patent RF na izobretenie № 2473083/20.01.2013. Yakubovskaya R. I., Nemtsova E. R., Karmakova T. A., Skripnik V. V., Pikin O. V., Rudakov R.V., Amiraliev A.M. Sposob prognozirovaniya posleoperatsionnykh oslozhnenii u bol'nykh s opukholevym porazheniem legkogo. URL: http://www.freepatent.ru/patents/2473083. Cited 12.05.2015. (In Russ)

43. Patent RF na izobretenie № 2486933/10.07.2013. Filonenko E. V., Vashakmadze L.A., Cheremisov V.V., Teplov A.A., Alekseev B. Ya., Smirnova S. V., Khomyakov V. M. Sposob profilaktiki retsidivov pri khirurgicheskom lechenii zlokachestvennykh opukholei malogo taza ili neorgannykh opukholei zabryushinnogo prostranstva. URL: http://www.freepatent.ru/patents/2486933. Cited 12.05.2015. (In Russ)

44. Patent RF na izobretenie № 2326704/20.06.2008. Osipova N. A., Khoronenko V.E. Sposob profilaktiki intra- i posleoperatsionnykh serdechno-sosudistykh oslozhnenii. URL: http://www.freepatent.ru/patents/2326704. Cited 12.05.2015. (In Russ)

45. Patent RF na izobretenie № 2410017/27.01.2011. Khoronenko V.E., Osipova N.A., Lagutin M. B., Shemetova M. M. Sposob otsenki riska razvitiya perioperatsionnykh serdechno-sosudistykh oslozhnenii pri vneserdechnykh khirurgicheskikh vmeshatel'stvakh. URL: http://www.freepatent.ru/patents/2410017. Cited 12.05.2015. (In Russ)

46. Patent RF na izobretenie № 2523565/20.07.2014. Sposob profilaktiki sindroma posleoperatsionnoi toshnoty i rvoty $v$ onkoginekologii. URL: http://www.freepatent.ru/patents/2523565. Cited 12.05.2015. (In Russ)

47. Patent RF na izobretenie № 2405546/10.02.2010. Tyurina N. G., Kobzeva I.V., Erastova E.I., Gracheva Z.D. Sposob profilaktiki i 
lecheniya enteropatii, razvivayushchikhsya na fone polikhimioterapii. URL: http://www.freepatent.ru/patents/2405546. Cited 12.05.2015. (In Russ)

48. Patent RF na izobretenie № 2382646/27.02.2010. Osipova N. A., Petrova V.V., Lastukhin A. V., Kudryavtsev S. B. Sposob profilaktiki i lecheniya posleoperatsionnogo bolevogo sindroma pri obshirnykh torakoabdominal'nykh operatsiyakh. URL: http://www. freepatent.ru/patents/2382646. Cited 12.05.2015. (In Russ)

49. Patent RF na izobretenie № 2446795/10.04.2012. Osipova N. A., Teplyakov V.V., Sobchenko L.A., Petrova V.V.Sposob predotvrashcheniya fantomnogo bolevogo sindroma posle amputatsii konechnostei. URL: http://www.freepatent.ru/patents/2446795. Cited 12.05.2015. (In Russ)

50. Patent RF na izobretenie № 2344762/27.01.2009. Kazakevich V.I., Mitina L.A. Sposob differentsial'noi diagnostiki patologicheskikh ob»emnykh obrazovanii v korne bryzheiki tonkoi kishki i/ili v bol'shom sal'nike. URL: http://www.freepatent. ru/patents/2344762. Cited 12.05.2015. (In Russ)

51. Patent RF na izobretenie № 2390025/27.12.2009. Khovanskaya T.P., Chissov V.I., Yurkov E.F., Kuz'min S.G., Shpak A.V., Shpigun O.A., Popik M.V., Sergeeva N.S., Gitis V.G., Pirogov S.A. Sposob prognozirovaniya opukholevykh zabolevanii molochnoi zhelezy. URL: http://www.findpatent.ru/patent/239/2390025.html. Cited 14.05.2015. (In Russ)

52. Patent RF na izobretenie № 2386968/20.04.2010. Chissov V.I., Khovanskaya T. P., Sergeeva N.S., Shpigun O.A., Popik M.V., ShpakA.V., Gitis V.G., Pirogov S.A., YurkovE.F., Kuz'min S.G. Sposob formirovaniya gruppy riska opukholevoi patologii molochnoi zhelezy. URL: http://www1.fips.

\section{Информация об авторах:}

1. Каприн Андрей Дмитриевич - д.м.н., профессор, членкорреспондент РАН, член-корреспондент РАО, Генеральный директор ФГБУ «НМИРЦ» Минздрава России

2. Александрова Лариса Митрофановна - к.б.н., заведующая отделением координации и внедрения научных исследований МНИОИ им. П.А. Герцена - филиала ФГБУ "НМИРЦ» Минздрава России

3. Старинский Валерий Владимирович - д.м.н., профессор, заместитель Генерального директора ФГБУ «НМИРЦ» Минздрава России
ru/fips_servl/fips_servlet?DB=RUPAT\&rn=6475\&DocNumber=2386968\&TypeFile=html. Cited 14.05.2015. (In Russ)

53. Patent RF na izobretenie № 2306868/27.09.2007. Chissov V.I., Reshetov I.V., Volchenko N.N., Slavnova E.N., Tychinskii V.P., Kretushev A. V., Klemyashov I. V. Sposob diagnostiki raka. URL: http://www.freepatent.ru/patents/2306868. Cited 14.05.2015. (In Russ)

54. Patent RF na izobretenie № 2437096/20.12.2011. Yakubovskaya R.I., Karmakova T.A., Volchenko N. N., Novikova E. G., Trushina O.I. Sposob formirovaniya gruppy riska neoplasticheskikh narushenii v epitelii sheiki matki. URL: http://www.freepatent. ru/patents/2437096. Cited 14.05.2015. (In Russ)

55. Patent RF na izobretenie patent № 2384297/20.03.2010. Yakubovskaya R.I., Nemtsova E.R., Karmakova T. A., Pikin O.V., Vursol D.A., Amiraliev A.M. Sposob prognozirovaniya posleoperatsionnykh oslozhnenii u onkologicheskikh bol'nykh. URL: http://www.freepatent.ru/patents/2384297. Cited 14.05.2015. (In Russ)

56. Patent RF na izobretenie patent № 2305494/10.09.2007. Mitina L.A., Kazakevich V.I., Sokolov V.V., Romanov D.V., Shumeiko A. E., Filonenko E.V., Sedykh S.A. Sposob ul'trazvukovoi otsenki effektivnosti konservativnoi protivoopukholevoi terapii. URL: http://www.freepatent.ru/patents/2305494. Cited 14.05.2015. (In Russ)

57. Patent RF na izobretenie patent № 2366951/10.09.2009. Zavalishina L.E., Andreeva Yu.Yu., Frank G.A., Petrov A.N., Bateva M. V. Sposob otsenki vaskulyarizatsii. URL: http://www. freepatent.ru/patents/2366951. Cited 14.05.2015. (In Russ)

Information about authors:

1. Kaprin Andrey Dmitrievich - PhD, MD, professor, corresponding member of RAS corresponding member of RAO, General director of the National Medical Research Radiological Centre of the Ministry of Health of the Russian Federation

2. Alexandrova Larisa Mitrofanovna - PhD., head of department of coordination and implementation of research, P. A. Hertsen Moscow Oncology Research Institute - branch of the National Medical Research Radiological Centre of the Ministry of Health of the Russian Federation

3. Starinskiy Valeriy Vladimirovich - MD, professor, vice director of director of P. A. Hertsen Moscow Oncology Research Institute branch of the National Medical Research Radiological Centre of the Ministry of Health of the Russian Federation

Оформление ссылки для цитирования статьи:

Каприн А.Д., Александрова Л.М., Старинский В.В. Реализация в клинической онкологической практике результатов инновационных научных исследований. Исследования и практика в медицине. 2015; 2(2): 53-62. DOI: 10.17709/2409-2231-2015-2-2-53-62

Kaprin A.D., Alexandrova L.M., Starinskiy V.V. Realization of results of innovational research in clinical oncological. Issled. prakt. Med. 2015; 2(2): 53-62. DOI: 10.17709/2409-2231-2015-2-2-53-62

Конфликт интересов. Все авторы сообщают об отсутствии конфликта интересов.

Conflict of interest. All authors report no conflict of interest. 